\title{
Alteration of $T$ helper cell subsets in the optic nerve of experimental autoimmune encephalomyelitis
}

\author{
A-YONG TIAN ${ }^{1}$, RONG-WEI ZHANG ${ }^{2}$, XIAO-GUANG SHI ${ }^{2}$ and HONG-MEI YU² \\ Departments of ${ }^{1}$ Anesthesiology; ${ }^{2}$ Neurology, the First Affiliated Hospital of China Medical University, \\ No. 155 Nanjing Bei Street, Heping, 110001 Shenyang, Liaoning, P.R. China
}

Received January 4, 2010; Accepted March 2, 2010

DOI: 10.3892/ijmm_00000416

\begin{abstract}
The objective of this study was to detect interleukin-17 (IL-17), interferon- $\gamma(\mathrm{IFN}-\gamma)$, interleukin-4 (IL-4) and forkhead/winged helix transcription factor p3 (Foxp3) protein and gene expression of the optic nerve and to further explore the role of T helper cell subsets such as Th1, Th2, Th17 and Treg in the pathogenesis of optic neuritis in experimental autoimmune encephalomyelitis (EAE). Mice in C57BL/6 background were randomly divided into control and EAE groups. At days 11, 15 and 19 post-immunization, optic nerves were dissected for morphological study to detect IL-17, IFN- $\gamma$ and IL-4. Protein analysis was done by enzyme-linked immunosorbent assay, quantitative real-time polymerase chain reaction for measuring the gene expression of IL-17, IFN- $\gamma$, IL-4 and Foxp3. Concentrations of IL-17 protein in the optic nerve were significantly up-regulated at 11 days postimmunization, and IFN- $\gamma$ protein concentrations at 19 days. Concentrations of IL-4 protein in the optic nerve declined slightly in 19 days. mRNA expression of IL-17, IFN- $\gamma$ and IL-4 was consistent with their protein expression. Foxp3 mRNA transcription was down-regulated at 11-19 days postimmunization. Decreased expression of Foxp3 mRNA and Treg in the optic nerve may play a key role in the development of optic neuritis. IL-17 may mediate inflammatory pathogenicity at the early stage of optic neuritis, and IFN- $\gamma$ may aggravate inflammatory injury during the peak stage of optic neuritis.
\end{abstract}

\section{Introduction}

Optic neuritis (ON) is an inflammation of the optic nerve (1). One of the most common complications of vaccination against viral pathogens and viral infections is acute ON (2-5). Typical characteristics in young adults are sudden monocular loss of vision accompanied by eye pain and it occurs more frequently

Correspondence to: Dr Rongwei Zhang, the First Affiliated Hospital of China Medical University, No.155 Nanjing Bei Street, Heping, 110001 Shenyang, Liaoning, P.R. China

E-mail: zhangrongwei916@sina.com

Key words: experimental autoimmune encephalomyelitis, optic nerve, interleukin-17, interferon- $\gamma$, interleukin-4, forkhead/winged helix transcription factor $\mathrm{p} 3$ in women than in men. $\mathrm{ON}$ is often observed in patients with multiple sclerosis (MS) $(6,7)$ and experimental autoimmune encephalomyelitis (EAE) in various animal species, including the mouse (5,8-11), rat (12), guinea pig (13), and primates $(14,15)$. Development of ON after induction of EAE suggests an autoimmune origin of the optic nerve inflammation observed in MS. Previous studies have demonstrated that MS is an autoimmune disease of the central nervous system (CNS) that appears to be mediated in part by T cells (16). Some studies have shown that regulatory $\mathrm{T}$ cells (Treg) play a critical role in the progression of the disease (17). T helper cells (Th) are also believed to contribute to pathogenesis, but the specific cell types involved are not well understood. Most studies usually focus on the injury of the brain and spinal cord, rather than the optic nerve. In the present study, we investigated optic neuritis induced by encephalitogenic peptides derived from myelin oligodendrocyte glycoprotein (MOG), to establish a working model for $\mathrm{ON}$, in nontransgenic mice on a $\mathrm{B} 6$ genetic background and to further determine the role of $\mathrm{T}$ helper cell subsets such as Th1, Th2, Th17 and Treg in the pathogenesis of optic neuritis in EAE.

\section{Materials and methods}

Materials. $\mathrm{MOG}_{35-55}$ peptide was synthesized and purified at CL (Xian) Bio-Scientific Co. Ltd. (China). Pertussis toxin (PT), mycobacterium tuberculosis and Complete Freund's adjuvant (CFA) were purchased from Sigma-Aldrich (USA). Cytokine ELISA kits were purchased from Boster Life Technologies (China). For real-time RT-PCR, all primers were purchased from Takara Life Technologies (Japan).

Mice. C57BL/6 (8-10 weeks old) female mice were purchased from Shanghai SLAC Laboratories animal Co. Ltd and were housed under a 12-h light/dark cycle in microisolater cages contained within a laminar flow system to maintain a pathogenfree environment. Experiments were conducted in accordance with the Animal Component of Research Protocol guidelines at the China Medical University.

Animal model of EAE. C57BL/6 mice were immunized by subcutaneous (s.c.) injection at two sites on the back with $200 \mu \mathrm{g} \mathrm{MOG}_{35-55}$ peptide dissolved in distilled water and emulsified with an equal volume of CFA supplemented with $4 \mathrm{mg} / \mathrm{ml}$ mycobacterium tuberculosis H37Ra. Intra-peritoneal 
Table I. Premier sets for real time PCR.

\begin{tabular}{lll}
\hline Cytokine & \multicolumn{1}{c}{ Forward } & \multicolumn{1}{c}{ Reverse } \\
\hline IL-17 & GTTCTGCTGCCT & CGGGCAATTACT \\
& GTCACATCATC & ATCAGTTCCTGTC \\
IFN- $\gamma$ & CGGCACAGTCAT & GTTGCTGATG \\
& TGAAAGCCTA & GCCTGATTGTC \\
IL-4 & TCTCGAATGTACC & AGCACCTTGG \\
& AGGAGCCATATC & AAGCCCTACAGA \\
Foxp3 & CAGCTCTGCT & TCGTCTGAAGG \\
& GGCGAAAGTG & CAGAGTCAGGA \\
GAPDH & TGTGTCCGTC & CCTGCTTCACC \\
& GTGGATCTGA & ACCTTCTTGA \\
\hline
\end{tabular}

injections were also given to all animals on days 0 and 2 with 400 ng PT. Control animals followed an identical immunization protocol (adjuvant + pertussis) without added MOG. Animals were weighed daily and assessed for clinical signs of EAE by two independent observers. We used the same clinical EAE scoring system to assess neurological deficit in our mouse EAE model according to the following scale: 0, no disease; 1 , loss of weight and tail weakness; 2 , weakness in hind limbs; 3 , complete hind limb paralysis; 4 , hind limb paralysis with fore limb weakness or paralysis; and 5, moribund or deceased.

Pathologic examination. Mice were anesthetized, exsanguinated, and perfused with $25 \mathrm{ml}$ PBS and $10 \mathrm{ml} 4 \%$ paraformaldehyde in buffered PBS. Optic nerves were dissected 11,15 and 19 days after immunization with $\mathrm{MOG}_{35-55}$ and fixed in $4 \%$ paraformaldehyde before embedding in paraffin. For histological study of $\mathrm{ON}$, whole eyes were collected, and immersed for $1 \mathrm{~h}$ in $4 \%$ phosphate-buffered glutaraldehyde, and then transferred to $10 \%$ phosphate-buffered formaldehyde until processed. Fixed and dehydrated tissue was embedded in methacrylate and $5 \mu \mathrm{m}$ sections were cut through the pupillaryoptic nerve plane and stained with hematoxylin and eosin. Evaluation of presence or absence of disease was masked by examining six sections cut at different levels for each eye.

Tissues for electron microscopy (EM). EM study were fixed in $2.5 \%$ gluteraldehyde in phosphate buffer $\mathrm{pH} 7.4$, post osmicated and processed routinely for EM examination. Transverse ultrathin sections of whole optic nerves were examined using H-600 transmission electron microscope.

ELISA for measurement of IFN- $\gamma, I L-17$ and IL-4. Concentration of cytokines was estimated by a sandwich immuno-assay procedure, using a combination of monoclonal and polyclonal antibodies, as described in the manufacturer's protocol (Boster).

Purification of mRNA and real-time RT-PCR. Total RNA was extracted from tissues using an RNA isolation kit (Takara). Complementary DNA was prepared as recommended and used as the template for quantitative PCR. Levels of mRNA for IL-4, IL-17, IFN- $\gamma$, and Foxp3 from optic nerves from all groups of mice were analyzed by RT-PCR. RT-PCR was performed according to the manufacturer's instructions. Primers

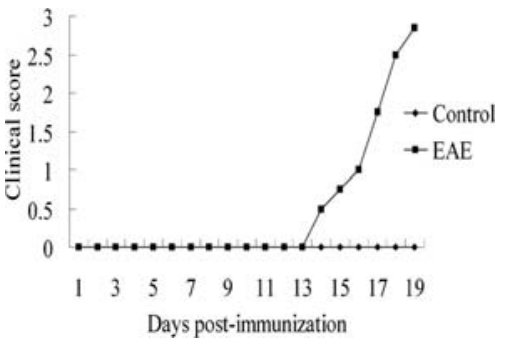

Figure 1. The course of EAE in MOG immunized mice. Clinical assessment of EAE was performed daily and mice were scored for disease according to the same criteria. The results are expressed as the mean daily clinical score of the experimental group.

were designed on different exons using primer express software and each PCR product was confirmed as a single band by agarose gel electrophoresis analysis. Then, $2 \mu 1 \mathrm{cDNA}$ from the superscript II reaction described above was mixed with $1 \mathrm{X}$ SYBR Green PCR Master mix, specific primer pairs, and deionized water in a total volume of $20 \mu 1$. PCR cycling conditions were $8 \mathrm{~min}$ at $95^{\circ} \mathrm{C}$ followed by 45 cycles of $95^{\circ} \mathrm{C}$ for $5 \mathrm{sec}, 60^{\circ} \mathrm{C}$ for $34 \mathrm{sec}$ and $72^{\circ} \mathrm{C}$ for $15 \mathrm{sec}$. The mRNA level for each sample was normalized against GAPDH mRNA. Specific primers are shown in Table I.

Statistical analysis. Data are expressed as the mean \pm SD. Student's two-tailed t-test was used to analyze the results. $\mathrm{P}$-values $\leq 0.05$ were considered significant.

\section{Results}

Histopathology in optic nerve of EAE mouse. MOG-treated mice developed severe clinical manifestations, starting on days 12-14, increasing in severity and resulting in death by day 19 . All animals were affected and mild or complete hind limb paralysis was observed in most animals. Fig. 1 shows the development of clinical signs of EAE in mice. To evaluate the inflammation and ultra structure of the optic nerve with the development of disease, optic nerves were examined by histological methods using light microscopy and eletron microscopy at 11, 15 and 19 days following MOG injection. H\&E staining (Fig. 2) and ultra structure observation (Fig. 3) revealed marked multifocal and lymphohistiocytic inflammation in white matter, which was both perivascular and diffused, and myelin loss in MOG-treated mice, especially around inflamed areas. Representative slides exemplifying optic nerve lesions are presented in Figs. 2 and 3.

Cytokine expression in the optic nerve of EAE mouse. Results in Fig. 4 show protein expression levels of IFN- $\gamma$, IL-17 and IL-4 by ELISA in the optic nerve at 11,15 and 19 days postimmunization. Significant increase in IL-17 at day 11 and IFN- $\gamma$ at day 19 post-immunization were detected in the optic nerve of wild-type mice immunized with MOG/CFA compared to wildtype mice immunized with CFA alone. The measurement of IL-4 declined comparatively at day 19 . The overall result demonstrates a significant increase in the expression of inflammatory cytokines in the optic nerve of the EAE mouse. The expression peak of IL-17 is earlier than IFN- $\gamma$, and there is an imbalance of IFN- $\gamma / \mathrm{IL}-4$ at 19 days post-immunization. 

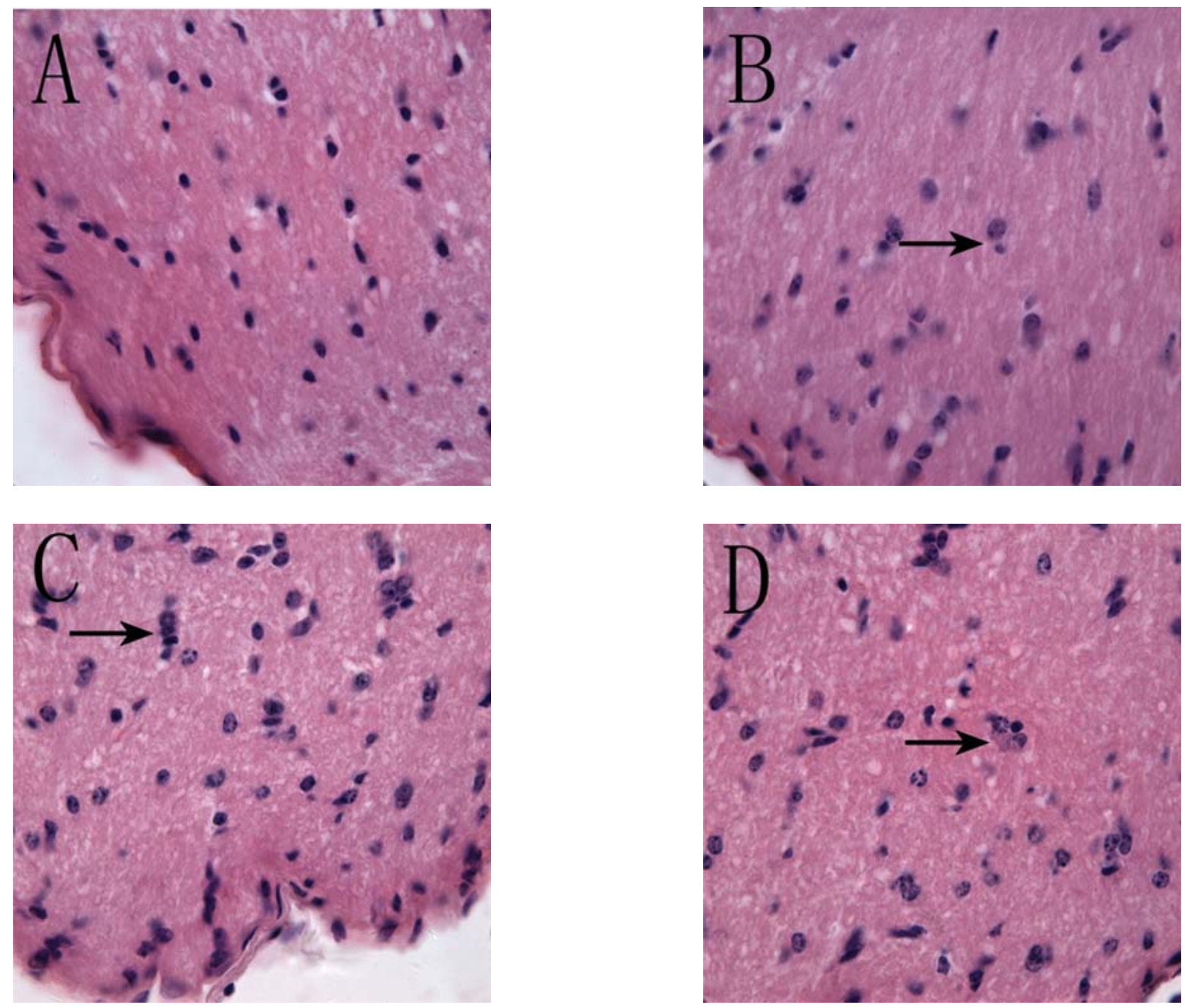

Figure 2. Emergence of infiltrates in the optic nerve of MOG-immunized mice in chronic EAE. Representative histopathology of optic nerve are shown for chronic MOG $_{35-55}$-induced EAE $(11,15$, and 19 days after immunization, B-D, respectively) and control group (A). Iinfiltrates are indicated by arrows in each panel. All images are at x1,000 magnification. H\&E staining.

Expresssion of cytokine genes in the optic nerve of EAE mouse. We examined the expression of four T helper cell subsets, Th1, Th2, Th17, Treg-specific cytokines IFN- $\gamma$, IL-4, IL-17 and Foxp3 genes, which are considered to play a critical role in EAE, especially when inflammation occurs in the brain and spinal cord, but little is known about their role in optic nerves. Expression of four cytokine genes were analyzed in the optic nerve at 11,15 and 19 days post-immunization by quantitative real-time RT-PCR. IFN- $\gamma$, IL-4 and IL-17 genes were consistent with their protein expression. But gene expression of Foxp3 was down-regulated at the early stage (11 days post-immunization ) before clinical signs occurred till its peak stage (19 days postimmunization). The above results suggest that a Foxp3/IL-17 imbalance exists in the early stage of optic neuritis in EAE mice, IFN- $\gamma /$ IL-4 imbalance may contribute to the peak injury of optic neuritis in EAE mice. Gene expression of the three cytokine is shown in Fig. 5.

\section{Discussion}

$\mathrm{ON}$ is an acute inflammatory demyelinating condition of the optic nerve often observed in 2 general settings, idiopathic and MS. In $\sim 20 \%$ of MS patients, ON is the presenting manifestation of the disease (clinically isolated demyelinating syndrome, CIS) (18). Furthermore, ON can occur at any point of time in the lifetime of a patient with MS approaching a frequency of $66 \%$ (19). Ninety percent of clinically definite MS (CDMS) patients have electrophysiological evidence of ON based on visual-evoked potentials (20). Based on several older retrospective studies, the conversion rate of $\mathrm{ON}$ to $\mathrm{MS}$ has varied widely ranging from 8 to $85 \%$ (21). The potential for conversion to MS highlights the importance of investigating ON.

EAE serves as an animal model that recapitulates many features of MS. It can be induced by immunization of susceptible animals with a number of myelin antigens including myelin basic protein (MBP) (22), proteolipid protein (PLP) (23-25), and myelin oligodendrocyte glycoprotein (MOG) (26). MOG, although a minor component, $\sim 0.05 \%$, of the myelin sheath, has been shown to be a potent encephalitogenic protein that induces EAE in many strains and species of experimental animals (27-31), and is also implicated in the pathogenesis of MS $(32,33)$. In EAE, the identity of the target auto antigen, at least in part, determines the disease phenotype and pattern of lesion distribution in the CNS. For example, immune responses to MBP or PLP induce lesions located predominantly in the 

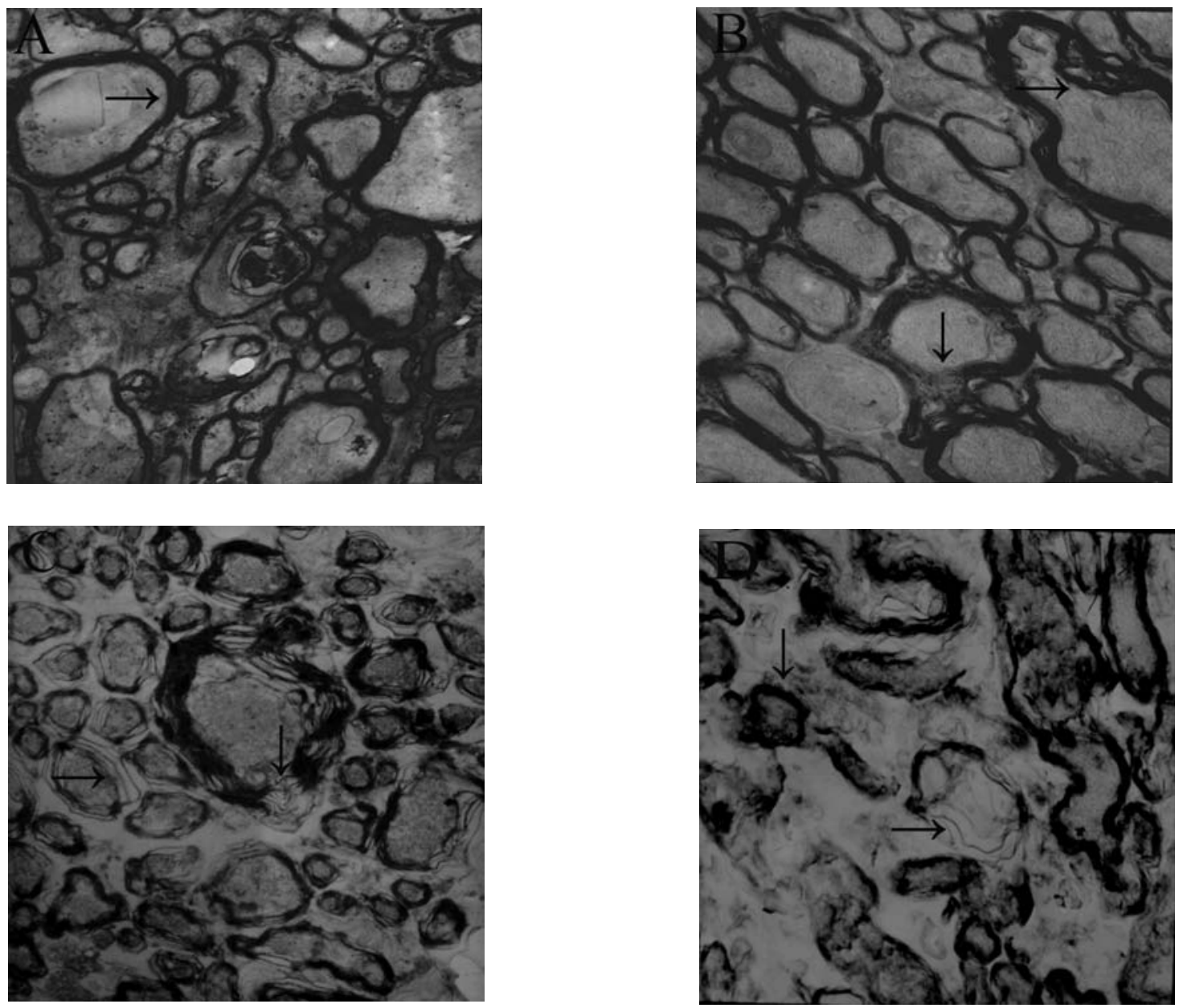

Figure 3. Ultra structure in the optic nerve of MOG-immunized mice in chronic EAE. Panels are arranged as in (A) normal optic nerve, complete myelin is present in the optic nerve. (B) Few loose myelin have been occasionally observed in the optic nerve of $\mathrm{M}_{11}\left(\mathrm{MOG}_{35-55}\right.$-induced EAE 11 days after immunization) group. (C) Many loose, fused myelin lying in the optic nerve of M15 ( $\mathrm{MOG}_{35-55}$-induced EAE 15 days after immunization) group. (D) A large amount of fragmented spires of myelin sheath were observed in the optic nerve of $\mathrm{M} 19\left(\mathrm{MOG}_{35-55}\right.$-induced EAE 19 days after immunization) group, the component of axonhas disappeared.

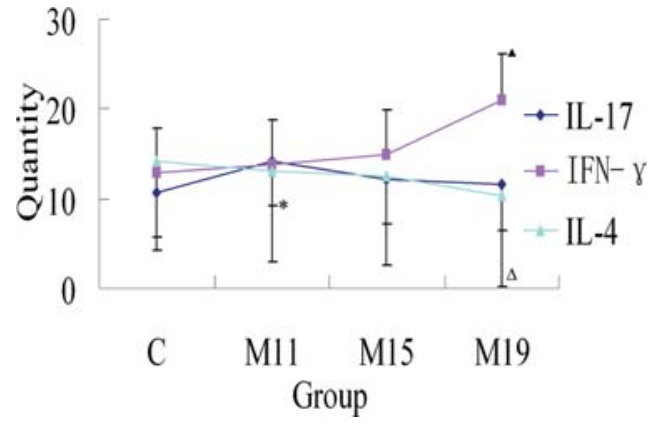

Figure 4. Expression of IL-17, IFN- $\gamma$, IL-4 proteins in the optic nerve. $\mathrm{MOG}_{35-55}$ immunized C57 mice. Optic nerves were obtained at three different time points (days 11, 15 and 19, M11, M15, M19 groups, respectively) from the first immunization with MOG or control group without MOG immunization (C group). The expression of IL-17, IFN- $\gamma$, IL-4 proteins in the optic nerve was quantified by ELISA. There is a substantial increase in the expression of IL-17 and IFN- $\gamma$ protein in EAE optic nerve at the time of 11 and 19 days post-immunization, respectively. Expression of IL-4 protein shows a comparative decrease at 19 days post-immunization. Data represent mean \pm SD for 4 individual mice. IL-17. ${ }^{*} \mathrm{p}<0.05$ vs group $\mathrm{C}$; IFN- $\gamma,{ }^{\wedge} \mathrm{p}<0.01$ vs group C; IL-4, $\triangle \mathrm{p}<0.05$ vs group C.

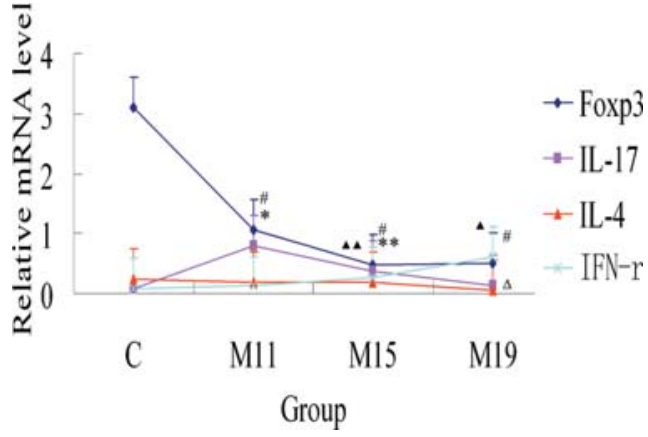

Figure 5. Expression of IL-17, IFN- $\gamma$, IL-4 mRNA in the optic nerve. Mice were immunized with MOG. Optic nerves were obtained at three different time points (days 11, 15 and 19; M11, M15, M19 groups) from mice immunized with MOG or control group without MOG immunization (C group). Expression of IL-17, IFN- $\gamma$, IL-4 mRNA in the optic nerve was quantified by real-time PCR. Gene expression of IL-17 and IFN- $\gamma$ in EAE optic nerve shows a significant increase at early stages (day 11) as well as at the peak of clinical signs (day 19) respectively compared to control group. Expression of IL-4 gene shows a comparative decrease at 19 days post-immunization. There is reduced gene expression of Foxp3 from the early stage (day 11) before a clinical sign occurred till the peak stage (day 19). Data represent mean $\pm \mathrm{SD}$ for 4 individual mice. IL-17, ${ }^{*} \mathrm{p}<0.01,{ }^{* *} \mathrm{p}<0.05$ vs group C; IFN- $\gamma,{ }^{\mathbf{\Delta}} \mathrm{p}<0.01$, $\triangle^{\Delta} \mathrm{p}<0.05$ vs group $\mathrm{C}$; IL-4, ${ }^{\Delta} \mathrm{p}<0.01$ vs group $\mathrm{C}$; Foxp3, ${ }^{\#} \mathrm{p}<0.01$ vs group $\mathrm{C}$. 
spinal cord whereas immunization with MOG generates mainly optic nerve and spinal cord lesions (34). Optic nerve lesions have been reported in some forms of EAE, but have always been associated with the presence of inflammation and demyelination of the brain and spinal cord (9,12,35-37). In the present study we take advantage of EAE, model of lesions located predominantly in the optic nerve, to observe the role of the main four $\mathrm{T}$ helper cell subsets Th1, Th2, Th17 and Treg during different stages of disease.

MS is an autoimmune disease of the CNS that perhaps is mediated in part by $\mathrm{T}$ cells (16). Historically, Th1 and Th2 cells have been characterized as two classic $\mathrm{CD}^{+}{ }^{+} \mathrm{T}$ cell subsets that secrete pro-inflammatory cytokines, such as IFN- $\gamma$, or anti-inflammatory cytokines, such as IL-4, IL-5, IL-10 and IL-13, respectively. Recent studies have identified two new $\mathrm{CD}^{+}{ }^{+} \mathrm{T}$ cell subsets in addition to the well-known Th1and Th2-like cells. One is the naturally thymus-born Foxp3+ $\mathrm{T}$ regulatory (Foxp $3^{+}$Treg) cell (36-38), which functions as an inhibitor of the initiation and/or development of certain immune cell responses, and are considered to be antiinflammatory in nature. The other is the T helper 17 (Th17) cell that secretes IL-17 and promotes inflammation and autoimmunity $(39,40)$. Because an inflammatory response in the CNS can cause neuronal damage and may be involved in the pathogenesis of several neurodegenerative diseases (41), it appears to be the Th1 and Th17 cells associated with EAE, which is characterized by neuronal degeneration and myelin degradation (42). In contrast, a shift in the immune response toward the activation of Th2 or Treg cells has been reported to delay neurodegenerative disease onset and/or inhibit disease progression (43-46). Therefore, in this study, we identified the phenotype of $\mathrm{CD}^{+}{ }^{+} \mathrm{T}$ cells that develop in optic neuritis in the EAE mouse model. The present result supports that all known $\mathrm{CD}^{+} \mathrm{T}$ cell subsets develop after optic nerve injury. The data show that (i) pro-inflammatory Th1 and Th17 cells increase after optic neuritis, and with a different cytokine expression peak by 11 and 19 days respectively; (ii) Anti-inflammatory Th2 and Treg cells show a decline in the optic nerve of EAE mice. The former decrease at 19 days after immunization, and the latter has an obvious down-regulation from 11 to 19 days after immunization. Here, we not only investigated the two classic $\mathrm{CD}^{+}{ }^{+} \mathrm{T}$ subsets, i.e., pro-inflammatory Th1 cells and anti-inflammatory Th2 cells, previously implicated in neural injury and repair, but also examined the development of the recently identified Th17, and Treg cells $(11,47)$. The data indicate that balance of $\mathrm{CD} 4^{+} \mathrm{T}$ subsets is crucial to keep immune homeostasis. Some diseases will occur once the balance is broken. While CD4 ${ }^{+} \mathrm{T}$ cell subsets mutually inhibit development of each other, recent evidence suggests that naive $\mathrm{T}$ cells (in mice) are induced to differentiate along a pathway favoring development of Th17 or Treg cells in a mutually exclusive manner $(11,48,49)$. Indeed, the Th17 population is important in mediating autoimmune diseases in animals $(50,51)$. As a result, a novel hypothesis has been proposed (39) with regards to inflammatory and autoimmune diseases, namely that skewing responses towards Th17 or Th1 and away from Treg (and Th2) may be responsible for the development and progression of autoimmune disease (AD) and that a blockade of critical cytokines may result in a shift in this polarization from Th17/Th1 phenotypes towards Treg and Th2 (i.e. that regulation and deregulation are inducible and remediable).

Our observations suggest that during the early stage of EAE, there is a imbalance of Th17/Treg cells in the optic nerve, but the imbalance of Th1/Th2 seen in the optic nerve occurs at a later stage of EAE. Treg cells show a significant role in the development of optic neuritis in EAE by down-regulating the gene expression from an earlier to a later stage, so its inhibit function to all $\mathrm{CD}^{+}{ }^{+} \mathrm{T}$ subsets, especially to Th1 and Th17 cells, declined obviously. Then we observed high expression of Th1 and Th17 cytokines. Th1 and Th17 cells are known as proinflammatory subsets. One of the major Th1 cell-derived cytokines is IFN- $\gamma$. IFN- $\gamma$ is a potent pro-inflammatory cytokine. The major cytokine secreted by Th17 cells is IL-17, which is involved in tissue inflammation and autoimmunity $(51,52)$. Expression of high levels of pro-inflammatory cytokines and chemokines in the CNS are thought to contribute to the initiation and maintenance of $\operatorname{EAE}(53,54)$. By contrast, anti-inflammatory Th2 cells were given a mild inhibition by Treg cell subsets and show a moderate decrease accordingly in the optic nerve of EAE.

We studied the role of four $\mathrm{T}$ helper cell subsets in the development of optic neuritis in EAE. We concluded that all $\mathrm{CD}^{+} \mathrm{T}$ cell subsets participate in the development of optic neuritis in EAE and imbalance of $\mathrm{CD}^{+} \mathrm{T}$ cell subsets may contribute to the pathogenesis of optic neuritis. We also observed an early increase of Th17 cell subsets and later increase of Th1 cell subsets, possibly a result from the decrease of Treg cell subsets in optic nerve of EAE. The detection of IL-17, IFN- $\gamma$ and Foxp3 gene expression in different stages of the disease will become an important diagnostic index. Cytokines will play a critical role in therapy and prevention of optic neuritis clinically by immune therapy, maintaining the balance of Thl7, Treg, Thl, Th2 cell subsets and inhibiting inflammation.

\section{Acknowledgements}

We thank Professor Teng Wei-Ping for helpful suggestions. The work was supported by grants from China Liaoning Province Education Department (No. 2009A733).

\section{References}

1. Kanski JJ: Clinical Ophthalmology: A Systematic Approach. 5th edition, Butterworth Heinemann, Philadelphia, 2003.

2. Sriram S and Steinman L: Postinfectious and postvaccinial encephalomyelitis. Neurol Clin 2: 341-353, 1984.

3. Stewart O, Chang B and Bradbury J: Simultaneous administration of hepatitis B and polio vaccines associated with bilateral optic neuritis. Br J Ophthalmol 83:1200-1201, 1999.

4. Kerrison JB, Lounsbury D, Thirkill CE, et al: Optic neuritis after anthrax vaccination. Ophthalmology 109: 99-104, 2002.

5. Guy J, Qi X and Hauswirth WW: Adeno-associated viralmediated catalase expression suppresses optic neuritis in experimental allergic encephalomyelitis. Proc Natl Acad Sci USA 95: 13847-13852, 1998.

6. Merle H, Cabre P, Poman G, et al: Optical involvement in multiple sclerosis: results of a cross-sectional study with 57 patients from Martinique (in French). J Fr Ophtalmol 24: 829-835, 2001.

7. Lycke J, Tollesson PO and Frisen L: Asymptomatic visual loss in multiple sclerosis. J Neurol 248: 1079-1086, 2001.

8. Milici AJ, Carroll LA, Stukenbrok HA, et al: Early eosinophil infiltration into the optic nerve of mice with experimental allergic encephalomyelitis. Lab Invest 78: 1239-1244, 1998. 
9. O'Neill JK, Baker D, Morris MM, et al: Optic neuritis in chronic relapsing experimental allergic encephalomyelitis in Biozzi $\mathrm{ABH}$ mice: demyelination and fast axonal transport changes in disease. J Neuroimmunol 82: 210-218, 1998.

10. Steinman L: Optic neuritis, a new variant of experimental encephalomyelitis, a durable model for all seasons, now in its seventieth year. J Exp Med 197: 1065-1071, 2003.

11. Bettelli E, Pagany M, Weiner HL, et al: Myelin oligodendrocyte glycoprotein-specific $\mathrm{T}$ cell receptor transgenic mice develop spontaneous autoimmune optic neuritis. J Exp Med 197: 1073-1081, 2003.

12. Hu P, Pollard J, Hunt N, et al: Microvascular and cellular responses in the optic nerve of rats with acute experimental allergic encephalomyelitis (EAE). Brain Pathol 8: 475-486, 1998.

13. Robin JB, Phillips TM and Rao NA: Anti-myelin basic protein antibody in experimental allergic optic neuritis and encephalomyelitis. Ophthalmic Res 17: 174-180, 1985.

14. Hayreh SS: Experimental allergic encephalomyelitis. II. Retinal and other ocular manifestations. Invest Ophthalmol Vis Sci 21: 270-281, 1981 .

15. Hayreh SS, Massanari RM, Yamada T, et al: Experimental allergic encephalomyelitis. I. Optic nerve and central nervous system manifestations. Invest Ophthalmol Vis Sci 21: 256-269, 1981.

16. Hohlfeld R and Wekerle H: Autoimmune concepts of multiple sclerosis as a basis for selective immunotherapy: from pipe dreams to (therapeutic) pipelines. Proc Natl Acad Sci USA 101: 14599-14606, 2004

17. Kasper LH, Haque A and Haque S: Regulatory mechanisms of the immune system in multiple sclerosis. T regulatory cells: turned on to turn off. J Neurol 254S, 10-14, 2007.

18. Confavreux C, Vukusic S, Moreau T, et al: Relapses and progression of disability in multiple sclerosis. N Engl J Med 343: 1430-1438, 2000.

19. Rodriguez M, Siva A, Cross SA, et al: Optic neuritis: a population based study in Olmsted County, Minnesota. Neurology 45: 244-250, 1995

20. Halliday AM, McDonald WI and Mushin J: Visual evoked response in diagnosis of multiple sclerosis. Br Med J 4: 661-664, 1973.

21. Kurtzke JF: Optic neuritis or multiple sclerosis. Arch Neurol 42: 704-710,1985.

22. Zamvil SS, Mitchell DJ, Moore AC, et al: T-cell epitope of the autoantigen myelin basic protein that induces encephalomyelitis. Nature 324: 258-260,1986.

23. Tuohy VK, Lu Z, Sobel RA, et al: Identification of an encephalitogenic determinant of myelin proteolipid protein for SJL mice. J Immunol 142: 1523-1527, 1989.

24. Greer JM, Kuchroo VK, Sobel RA and Lees MB: Identification and characterization of a second encephalitogenic determinant of myelin proteolipid protein (residues 178-191) for SJL mice. J Immunol 149: 783-788, 1992

25. Greer JM, Sobel RA, Sette A, et al: Immunogenic and encephalitogenic epitope clusters of myelin proteolipid protein. J Immunol 156: 371-379, 1996.

26. Mendel I, Kerlero de Rosbo N and Ben-Nun A: A myelin oligodendrocyte glycoprotein peptide induces typical chronic experimental autoimmune encephalomyelitis in $\mathrm{H}-2 \mathrm{~b}$ mice: fine specificity and $\mathrm{T}$ cell receptor $\mathrm{V}$ beta expression of encephalitogenic T cells. Eur J Immunol 25: 1951-1959, 1995

27. Linington C, Berger T, Perry L, et al: $\mathrm{T}$ cells specific for the myelin oligodendrocyte glycoprotein mediate an unusual autoimmune inflammatory response in the central nervous system. Eur J Immunol 23: 1364-1372,1993.

28. Amor S, Groome N, Linington C, et al: Identification of epitopes of myelin oligodendrocyte glycoprotein for the induction of experimental allergic encephalomyelitis in SJL and Biozzi $\mathrm{AB} / \mathrm{H}$ mice. J Immunol 153: 4349-4356, 1994.

29. Kerlero de Rosbo N, Mendel I and Ben-Nun A: Chronic relapsing experimental autoimmune encephalomyelitis with a delayed onset and an atypical clinical course, induced in PL/J mice by myelin oligodendrocyte glycoprotein (MOG)-derived peptide: preliminary analysis of MOG T cell epitopes. Eur J Immunol 25: 985-993, 1995.

30. Genain CP and Hauser SL: Allergic encephalomyelitis in common marmosets: pathogenesis of a multiple sclerosis-like lesion. Methods 10: 420-434, 1996

31. Adelmann M, Wood J, Benzel I, et al: The N-terminal domain of the myelin oligodendrocyte glycoprotein (MOG) induces acute demyelinating experimental autoimmune encephalomyelitis in the Lewis rat. J Neuroimmunol 63: 17-27, 1995.
32. Kerlero de Rosbo N, Milo R, Lees MB, et al: Reactivity to myelin antigens in multiple sclerosis. Peripheral blood lymphocytes respond predominantly to myelin oligodendrocyte glycoprotein. J Clin Invest 92: 2602-2608, 1993.

33. Sun J, Link H, Olsson T, et al: T and B cell responses to myelinoligodendrocyte glycoprotein in multiple sclerosis. J Immunol146: 1490-1495, 1991.

34. Berger T, Weerth S, Kojima K, et al: Experimental autoimmune encephalomyelitis: the antigen specificity of $\mathrm{T}$ lymphocytes determines the topography of lesions in the central and peripheral nervous system. Lab Invest 76: 355-364, 1997.

35. Raine CS, Traugott U, Nussenblatt RB, et al: Optic neuritis and chronic relapsing experimental allergic encephalomyelitis: relationship to clinical course and comparison with multiple sclerosis. Lab Invest 42: 327-335, 1980.

36. Beissert S, Schwarz A and Schwarz T: Regulatory T cells. J Invest Dermatol 126: 15-24, 2006.

37. Sakaguchi S, Sakaguchi N, Asano M, et al: Immunologic selftolerance maintained by activated $\mathrm{T}$ cells expressing IL-2 receptor alpha-chains (CD25). Breakdown of a single mechanism of selftolerance causes various autoimmune diseases. J Immunol 155: 1151-1164, 1995 .

38. Asano M, Toda M, Sakaguchi N, et al: Autoimmune disease as a consequence of developmental abnormality of a $\mathrm{T}$ cell subpopulation. J Exp Med 184: 387-396, 1996.

39. Weaver CT, Harrington LE, Mangan PR, et al: Th17: an effector CD4 $\mathrm{T}$ cell lineage with regulatory $\mathrm{T}$ cell ties. Immunity 24 : 677-688, 2006.

40. Harrington LE, Mangan PR and Weaver CT: Expanding the effector CD4 T-cell repertoire: the Th17 lineage. Curr Opin Immunol 18: 349-356, 2006.

41. Gilgun-Sherki Y, Melamed E and Offen D: Anti-inflammatory drugs in the treatment of neurodegenerative diseases: current state. Curr Pharm Des 12: 3509-3519, 2006.

42. Gocke AR, Cravens PD, Ben LH, et al: T-bet regulates the fate of Th1 and Th17 lymphocytes in autoimmunity. J Immunol 178: 1341-1348, 2007.

43. Town T, Vendrame M, Patel A, et al: Reduced Th1 and enhanced Th2 immunity after immunization with Alzheimer's betaamyloid(1-42). J Neuroimmunol 132: 49-59, 2002.

44. Mei FJ, Osoegawa M, Ochi H, et al: Long-term favorable response to interferon beta-1b is linked to cytokine deviation toward the Th2 and Tc2 sides in Japanese patients with multiple sclerosis. J Neuro Sci 246: 71-77, 2006.

45. Matejuk A, Buenafe AC, Dwyer J, et al: Endogenous CD4+BV8S2- $\mathrm{T}$ cells from TG BV8S2+ donors confer complete protection against spontaneous experimental encephalomyelitis (Sp-EAE) in TCR transgenic, $\mathrm{RAG}^{-/-}$mice. J Neurosci Res 71: 89-103, 2003

46. Schwartz $\mathrm{M}$ and Kipnis J: Therapeutic T cell-based vaccination for neurodegenerative disorders: the role of $\mathrm{CD} 4{ }^{+} \mathrm{CD} 25^{+}$ regulatory T cells. Ann NY Acad Sci 1051: 701-708, 2005.

47. Cottrez F and Groux H: Specialization in tolerance: innate $\mathrm{CD}(4+) \mathrm{CD}(25+)$ versus acquired TR1 and TH3 regulatory T cells. Transplantation 77: S12-S15, 2004.

48. Veldhoen M, Hocking RJ, Atkins CJ, et al: TGFbeta in the context of an inflammatory cytokine milieu supports de novo differentiation of IL-17-producing T cells. Immunity 24: 179-189, 2006.

49. Mangan PR, Harrington LE, O'Quinn DB, et al: Transforming growth factor-beta induces development of the $\mathrm{T}(\mathrm{H}) 17$ lineage. Nature 441: 231-234, 2006.

50. Lubberts E, Joosten LA, van de Loo FA, et al: Overexpression of IL-17 in the knee joint ofcollagen type II immunized mice promotes collagen arthritis and aggravates joint destruction. Inflamm Res 51: 102-104, 2002

51. Langrish CL, Chen Y, Blumenschein WM, et al: IL-23 drives a J Exp Med 201: 233-240, 2005.

52. Kolls JK and Linden A: Interleukin-17 family menbers and inflammation. Immunity 21: 467-476, 2004.

53. Godiska R, Chantry D, Dietsch GN and Gray PW: Chemokine expression in murine experimental allergic encephalomyelitis. J Neuroimmunol 58: 167-176, 1995.

54. Ransohoff RM, Glabinski A and Tani M: Chemokines in immune-mediated inflammation of the central nervous system. Cytokine Growth Factor Rev 7: 35-46, 1996. 